\title{
Computer Coding and Choreography: Contrasting Experiences of Learning About Collaboration in Engineering and Creative Arts
}

\author{
Nicholas Rowe \\ University of Auckland, Auckland, New Zealand \\ https://orcid.org/0000-0001-7304-1047 \\ Rose Martin \\ Norwegian University of Science and Technology, Trondheim, Norway \\ https:// orcid.org/0000-0003-1732-2666 \\ Nasser Giacaman \\ University of Auckland, Auckland, New Zealand \\ https:// orcid.org/0000-0001-6885-1571
}

\begin{abstract}
This article argues that how collaboration is taught can have a significant impact on the ways in which collaboration is experienced, understood and valued. In doing so, the study draws attention to performing arts studio-pedagogies, and their potential relevance to enhancing creativity within science, technology, engineering, and mathematics (STEM) education. Through a mixed-methods study of teachers' and students' experiences of group work, this article compares two disciplines that maintain distinct discourses on teaching collaboration: Software design and choreography. The quantitative data reveals that despite significant demographic differences, students from the two disciplines maintain a common enthusiasm for group learning. There are significant distinctions however, on student perceptions of the teaching and learning of collaboration, their learning achievements about group work, and the relevance of group work in their discipline. Qualitative commentaries from students and teachers extend the arguments across both the distinctions and the similarities, emphasizing the impact of particular teaching practices and establishing standpoints for further research into the pedagogy of collaboration in higher education.
\end{abstract}

Keywords: collaboration; choreography; group-work; pedagogy; software design 


\section{Introduction}

The ability to effectively collaborate is a key professional competence within the knowledge economies of the 21st century. As a result, 'collaboration' has become ubiquitous as a graduate attribute across tertiary education programmes (Burbach, Matkin, Gambrell \& Harding, 2010). While often referred to as a 'soft skill', an ability to collaborate can be as valuable to employers as the 'hard-skill' comprehension of domain-specific knowledge, as group collaboration can develop more creative ideas than individuals working in isolation (McMahon, Ruggeri, Kammer \& Katsikopoulos, 2016). Collaboration allows professionals to contribute to creative strategies and ideas, extend a sense of purpose, agency and motivation to others in the workplace, and thereby enhance the prospects of a collective venture (Hung, Durcikova, Lai \& Lin, 2011). How students experience learning about collaboration can therefore have a significant impact on their professional future.

The ability to collaborate has often been assumed by educators to be an innate behavior or characteristic, which can simply be enhanced by practice (Hesse, Care, Buder, Sassenburg \& Griffin, 2015). Evidencing this practice within the curriculum has generally involved the assessment of small-group tasks, in which students collaborate to solve problems and/or design solutions (Griffin \& Care, 2015). In many contexts, the assignment of a collaborative task is where the teaching of collaboration starts and ends, following the educational proposition that "the best way to learn about working together is by doing it" (Horder, 1995, p.158). Collaboration is a complex skill and disposition however, which can actually be taught and learnt through exposure to diverse approaches, guidance into deeper reflection and relevant application within specific disciplinary contexts (Hesse et al, 2015). Within this article we argue that students can experience significantly different teaching approaches to collaborative groupwork assignments, which can impact how they subsequently value those learning experiences, and how they perceive the relevance of collaboration within their discipline.

To deeply understand the ways that teaching through small group tasks can impact on students' experiences of learning about collaboration, we engaged in a multi-phase cross-faculty study. This study investigated teaching practices within two programmes in our institution that approach collaborative coursework in very distinct ways: Software design and choreography. While previous research has investigated the significance of integrating arts learning within engineering education to enhance creativity, our cross-disciplinary comparative analysis seeks to go a step further: to enhance understandings of how and why specific creative arts studio-pedagogies (rather than practices) might be transferred across disciplines, to advance the teaching of creativity and collaboration within STEM subjects in tertiary education.

The pedagogic distinctions between choreography and software design presented here extend beyond the particular practices of individual teachers, and can be seen as rooted within the educational discourses of these two disciplines, and the wider educational discourses of engineering and creative arts (Rowe, 2019). Our article 
therefore begins with a consideration of how collaboration has been theorized within educational literature, and its relevance to the domains of dance and software design. This leads into a review of our mixed-methods approach to this study.

We then explore the themes that emerged from our research into students and teachers of software design and choreography. Interviews with teachers and classroom observations revealed that teachers from both groups value collaborative coursework as relevant to the students' professional futures, yet their approaches to teaching group work are markedly different. Our student data reveals that while students in both groups hold generally similar attitudes towards group projects in class, there is a marked difference in how the two student groups feel that they are taught about collaboration, what they feel that they learn about working in groups, and ultimately how relevant they think group work is to their discipline. These findings support our argument that how collaboration is taught can have a significant impact on how students learn and value group tasks within coursework. This suggests the need for further research into how tertiary educators teach collaboration, and the potential transference of pedagogic strategies from creative arts to engineering.

\section{Collaboration in work and education: software design and choreographic arts}

In professional contexts, collaboration requires individuals to contribute (and accommodate) divergent perspectives within the development of innovative products and services. This distinguishes collaboration from more pervasive, industrialized models of professional collective endeavor, like cooperation. Through cooperation, individuals provide (often highly skilled) labour to an enterprise, without necessarily engaging in processes of collective deliberation on the nature of that enterprise (Mattessich \& Monsey, 1992). The collective deliberation that distinguishes collaboration from cooperation can require individuals to engage in promotive relationships (Johnson \& Johnson, 2009) that maintain a sense of symmetry (Dillenbourg, 1999) and value pluralism (Owen, 2015) when making collaborative decisions. Participating in such creative decision-making can be self-actualizing for individuals within an enterprise (Csikszentmihalyi, 1996). Research has further shown that the more motivated that collaborators are to support the success of the collective enterprise (rather than motivated by just an economic exchange for their contributions), the more valuable their contributions tend to be towards the creative outcomes (Hung et al, 2011). Developing a collaborative disposition can therefore be seen as an important professional competence, which can require learning processes that enhance both collaborative skills and collaborative motivations.

Within education, collaboration is often associated with small-group learning, in which students interact on creative tasks related to the subject being studied. Small-group learning is not new in education: such peer-to-peer activity has been a central tenet of progressive education systems for the last half century (Rodgers, 1982). It is important to note however, that such peer-learning relationships were not introduced into formal education in order to enhance students' abilities to 
collaborate; small-group work was introduced with the goal of advancing individual student achievement (Hennessy \& Murphy, 1999). The need for students to learn to collaborate (rather than through collaboration) came later, in response to industry demands that graduates have an enhanced capacity to effectively innovate in teams (Boden \& Nedeva, 2010). The distinction between learning to and learning through collaboration has not been pervasively recognized within much of the literature on collaborative learning in higher education (Griffin \& Care, 2015). This can lead tertiary educators to suppose that simply engaging in small-group tasks is sufficient to learn about collaboration, sustaining the belief that "the sheer amount of interaction [. . .] is a powerful predictor of learning" (Cohen, 1994, p.16). Transitioning into a collaborative mindset can be a complex process, requiring students to adapt their social relationships, conceptual understandings and personal inclinations. This can demand deliberate pedagogic actions that constructively align the graduate attribute of collaboration with curricula design, teaching activities, learning resources and assessment strategies (Biggs, 1996).

So how and why is collaboration relevant to professional contexts and tertiary courses in software design and choreography? The teaching approaches to collaboration in dance and engineering will inevitably vary across classrooms and institutions, and our research does not seek to establish firm pedagogic categories within software design and choreography. It is possible to note, however, that the teaching practices that are described within this study are not random illustrations of personal pedagogic preferences but fit within the predominant discourses associated with teaching collaboration within these disciplines, which we summarize below.

Software design involves the development of digital programs that provide a service to the users of digital devices. While writing code is an integral part of software design, software engineers also engage in non-coding tasks such as gathering requirements from clients, brainstorming concepts, executing designs, testing new programs and documenting processes. Due to the increasing complexity of modern software, development requires the participation of multiple individuals working together and consulting each other (Whitehead, 2007). The concept of collaboration is therefore not new to the profession of software engineering, as the process of partnering in code writing and engaging stakeholders in the design process has long been encouraged (Beck, 2000). Project management systems such as Agile have evolved from software design (Cockburn, 2006), promoting the use of collaboration within other project management contexts, as a means of enhancing productivity, innovation and social capital within the knowledge economy workplace (Barksdale \& McCrickard, 2012; Dawson \& Jones, 2003).

The valuing of collaboration within the profession of software engineering has led to a valuing of collaboration within tertiary education programmes that teach software design. This has involved the integration of small-group tasks within the assessments of software engineering degrees, to emulate scenarios that students will encounter in professional life. Incorporating these group tasks into the 
software design curriculum has increasingly involved the use of online communication systems, which identify the quantity and quality of each collaborator's contribution (Soller, Martinez, Jermann \& Muehlenbrock, 2005), allowing teachers to monitor and measure free riding (Jermann \& Dillenbourg, 2008). While a growth in digital tools have sought to support parity in assessment, less scholarly attention has been given to the deliberate teaching of collaboration in these classrooms (Hesse et al, 2015).

The discipline of choreography involves the design of dance movement for presentation by dancers (Lavender \& Predock-Linell, 2001), within dance contexts that range from professional performances to more social/participatory events (Nahachewsky, 1995). While the physical interaction of dance inevitably requires social engagement, the choreographic process does not inherently involve collaboration, and the creative leadership of choreography can range from authoritarian to egalitarian (Butterworth, 2004). Within the 21st century however, professional choreographers are increasingly required to engage in collaborative processes with other choreographer/performers from diverse genres, cultural backgrounds and physical capabilities, and artists from other disciplines, during diverse phases of the creative production process (Foster-Sproull, 2017). With the expansion of dance as a professional practice beyond concert hall contexts, the development of choreographic competencies has come to include education, social development and entrepreneurial applications of dance (Lehikoinen, 2018).

In tertiary degree programmes, choreography is taught as both a specific subject and as an integral component of general courses on performance, exploring how to improvise to generate or interpret movement (Rowe \& Zeitner-Smith, 2011) and pedagogy, exploring how to facilitate the creative practices of others (Lavender, 2009). Choreography is generally taught through experiential learning in studio settings, where students review the dances and creative processes of others and actively create their own dances (Van Dyke, 2005). This can involve collaborative practices with other students to explore ideas, and develop group choreographic work for assessment. Such learning generally involves a scaffolding of collaborative processes, so that students are actively collaborating with each other on small, non-assessed tasks in lessons before moving to assessed group work (Buck \& Rowe, 2015). These teaching practices have sought to emphasize the importance of collaboration amongst students, as a means of engaging in social animation (Thapalia, 1996) with diverse groups, cultures and body types (Amans, 2017).

Both software design and dance value collaboration as a graduate attribute in alignment with wider trends in 21st century creative economies, yet our research suggests that how tertiary educators approach the teaching of this graduate attribute can be markedly different. Within the classrooms participating in our study, collaborative innovation in software design is generally valued as a means of enhancing productivity (Giacaman \& Sinnen, 2018), whereas collaborative innovation in choreography is generally valued as a means of enhancing selfactualization, pluralism and inclusion (Buck \& Snook, 2018). This opens questions as to how these differing mandates may play out in the classroom. What do these 
two cohorts of students feel about group-work in general? How do they experience the teaching of collaboration? How do they feel that small-group learning has helped them develop relevant, professional skills?

\section{Methodology}

To address these questions, our mixed-methods research engaged a grounded theory approach, with an iterative, hermeneutical literature review into the teaching of collaboration in higher education. This occurred in tandem with a qualitative exploration (Denzin \& Lincoln, 1998) of the teaching of collaboration in Dance Studies and Software Engineering within our institute, including classroom observations (Dingwall, 1997) and semi-structured interviews (Weiss, 1994) with 4 teachers in each discipline. This revealed significant differences in the approach to teaching collaboration within our institution, which led us to posit that how students are taught collaboration can impact on their experience of learning about collaboration.

To investigate student perceptions of collaboration in coursework, we subsequently developed an online survey, which included five closed-ended demographic questions, 20 statements seeking agreement or disagreement along a 5-point Likert Scale, and four open-ended questions seeking qualitative commentary. The survey sought responses from students in the first four years of degree study in Dance Studies and Software Engineering at the University of Auckland, and data was gathered from approximately one-third of the students enrolled in each of the disciplines (111 participants). The research was undertaken under the auspices of the University of Auckland Human Participant Ethics Committee. To maintain participant anonymity and mitigate coercion, postgraduate research assistants were employed to interview the teachers, administer the survey and collate the data through Qualtrics (Rowe, Martin, Buck \& Mabingo, 2020) for an application of the process and outcomes).

Within this article, we draw on the quantitative and qualitative data from the interviews and survey to compare Software Engineering and Dance Studies students' perspectives on their experiences of learning about collaboration at university. We have selected 15 of the questions most relevant to collaboration and group-tasks and clustered these into four thematic sections based on A) attitudes towards collaboration, B) the pedagogy of collaboration, C) perceived learning about collaboration, and D) relevance of collaboration to discipline. The quantitative results are presented in bar charts at the beginning of each section. A 5-point Likert Scale (5=Strongly Agree, 4=Agree, 3=Neutral, 2=Disagree and $1=$ Strongly Disagree) is used to map the range of responses to each question, allowing for a two-tailed $t$-test to be performed comparing the two independent samples. The resulting $\mathrm{t}$-value is a standardized score representing the difference between the two groups, while the p-value is the probability these results occurred purely by chance. Through this process we sought to reveal contrasts and similarities between students in Software Engineering and Dance Studies, with the null hypothesis being that there are no differences in perspective between the two groups. We extend our quantitative analysis of these points with a 
qualitative analysis (Creswell, 2016) that draws on relevant quotations from the teacher interviews and the open-ended qualitative commentary of the students.

\section{Discussion}

It is worth noting that there were significant demographic distinctions between the two groups of participants. In the Choreography cohort, $78 \%$ identified as female and $38 \%$ as ethnically Māori/Pasifika. In contrast, in the Software Engineering cohort, only $23 \%$ identified as female and $3 \%$ as ethnically Māori/Pasifika. As the following analysis reveals, these demographic and disciplinary distinctions do not appear to transform into differences in attitude towards collaboration. As evidenced in the first section, students in Dance Studies and Software Engineering share a common feeling towards learning and working in groups and the null hypothesis is retained. This supports our proposition that demographic factors such as gender, cultural background or even chosen discipline are not a significant factor in determining student attitudes towards engaging in group work in class.

The null hypothesis is subsequently rejected, and greater distinctions emerge between these two groups within the following sections however, which examines how collaboration has been taught in each discipline, what students feel they have learnt through group work, and how students subsequently value group-work in their studies and profession. This supports our proposition that students' sense of learning about collaboration and their valuing of collaboration as a professional skill can be impacted by how they experience learning about collaboration within their discipline.

\section{What does learning and working together feel like?}

The only null hypothesis we could confidently reject in figure A was A1 ( $t=2.3443$, $p=0.0209$ ). This evidenced that dance studies students were less likely to dread group learning activities than their software engineering peers. Both groups showed little difference in opinion in relation to their preference of not working on coursework alone ( $\mathrm{A} 2 \mathrm{t}=1.0293, \mathrm{p}=0.3056)$; to view group work as conducive to a positive in-class environment $(\mathrm{A} 4 \mathrm{t}=1.4056 \mathrm{p}=0.1627)$; and to view group interactions positively (A5 $\mathrm{t}=1.0247 p=0.3078$ ). Despite this, both groups' responses were comparably negative for prompt $A 3(t=-0.4068, p=0.685)$. In this regard, there was no statistically significant difference in both groups' opinion in viewing workloads as unevenly distributed in class. 


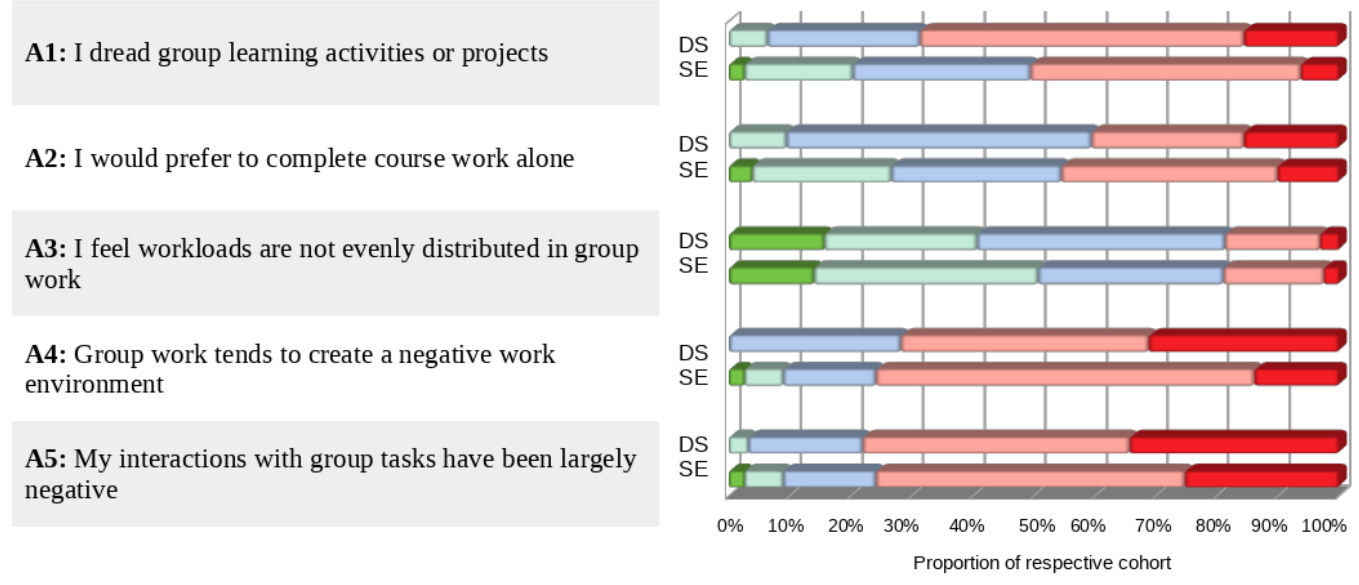

Figure A: Learing and working together

This corresponded with the comments from teachers in both disciplines, and how they perceived student attitudes towards group work. As a software design teacher reflected, "I'd say in general they're quite keen and excited to be working together." Within our student commentary, both groups expressed the enjoyment experienced working in groups, with numerous Software Engineering students expressing a desire for "more of them!". Their comments emphasized how socialization can increase the enjoyment of a course, through the idea of having "fun with friends" and the suggested equation "social aspect = more fun".

While the socialized learning was enjoyed by both groups, half of the Software Engineering students did not refuse the proposition that group learning and projects gave rise to dread. This prompts questions as to what is it about group learning that these students dread (especially given their more positive expressions towards socialized learning activities), and how might this dread be extended or mitigated by pedagogic actions. As both groups identified the uneven distribution of workloads in group tasks, this may be a starting point for understanding student apprehensions towards group work. A choreography student expressed concerns over "people who slack off", and a software design student emphasized the need to "ensure people pull their weight". This concern over 'free riders' (Fehr \& Gachter, 2002) was a sentiment shared by students in both groups, although amongst software design students there were comments seeking punitive actions to "enforce participation" and "keep people more accountable for their contributions". A desire for external monitoring of contribution aligns with the broader discourse in software design education literature, and the development of extensive software programs for engineering courses that measure and quantify an individual's communications and contributions to group projects (Jermann \& Dillenbourg, 2008).

Activating people to effectively work together can be considered central to the theme of teaching (and qualifying) students to collaborate. How teachers rationalize student non-engagement in collaboration can, however, vary. A software design teacher associated this 'free-riding' with student capability, explaining how "Weak students could surf through the course with group work, because 
sometimes the strong ones pull them through and many students will not feel comfortable to complain." By contrast, the choreography teachers tended to attribute student non-contribution to the complexities of engaging in collaborative endeavour, identifying how "all the social stuff combined with the creative stuff can cause a bit of confusion and discomfort."

This perceptual difference might be associated with notably distinct pedagogic approaches. From our interviews with teachers and observations of classes in both disciplines, two factors might be considered here: when group work takes place, and how it is scaffolded.

Firstly, within the software design courses, the small group tasks took place entirely outside scheduled lesson time. As a software teacher explained, "...it's not like group work where we expect them to do the work in front of us. ... these assignments take a long amount of time and it's kind of implied that they'll be doing that as their homework."

This contrasted with the choreography course, in which small group tasks occurred extensively during class time. As a choreography teacher described, "most of what we do is small-group-based learning." While experiential learning is an established convention within the studio-based learning of dance, the progression to more active learning environments is becoming increasingly promoted in software engineering (Chen, Wang, Kinshuk \& Chen, 2014). The idea that more class-time should be dedicated to group tasks was a recurrent theme within the comments offered by Software Engineering students, who sought, "more facilitated time allocated for collaboration" "Less lectures, more meetings" "More in-course opportunities for group work". This aligns with research that affirms student interest in more collaborative activities within class time (Freeman, Eddy, McDonough, Smith, Okoroafor, Jordt \& Wenderoth, 2014).

Secondly, within the choreography courses, these in-class tasks allowed students to progress from smaller, unassessed group tasks to more complex, assessed group tasks. A choreography teacher described how "...we are trying to just scaffold them as much as we can, so they can build up to that." Another choreography teacher rationalized the importance of non-assessed group tasks, explaining that "the whole premise behind that incremental development is to build confidence" in collaboration. By contrast, within software design, group tasks were only introduced as assessment items, usually halfway through the semester. This was rationalized by a software design teacher as logistical issue within the time frame of the institutional learning, explaining that "There's no time to do group activities that are not leading to a grade." When an assessed group-activity is suddenly introduced to an otherwise private learning experience however, students can feel underprepared for both the social and cognitive challenges presented by the task (Hesse et al, 2015). As a software student suggested,

"Start earlier in the degree. Start in the classroom, with smaller exercises that aren't worth grades. Do it often. Build up a culture of working together. Extend that out to assessments as soon as you can, trying to get students to work together as often as it makes sense." 
From the two programmes studied within our research, the scaffolding of group tasks and the incorporation of group activities into class time represent significantly contrasting pedagogic strategies. Do these distinctions explain why software students expressed a greater sense of dread towards group work? As the following section reveals, there were also significant distinctions in how collaboration was actually taught.

\section{How was collaboration taught?}

Figure B shows the results for prompts on the teaching of collaboration. Statistically significant differences were evidenced in all figure B prompt results, leading to our rejection of each null hypothesis - these results illustrating a marked difference in positive responses in favor of choreography students. Prompt B1 confirms choreography students were significantly more likely to agree that teacher enthusiasm motivated their collaboration $(\mathrm{t}=4.8248, \mathrm{p}<0.0001)$. This distinction is extended within B2 as choreography students more positively identified the role of teachers in facilitating collaboration $(t=4.8248, p<0.0001)$. Choreography students were also significantly more likely to agree that teachers outlined effective theories and practices for collaboration $(B 3, t=7.1950, p<0.0001)$ and that course outline and materials outlined effective theories and practices for collaboration (B4, $t=5.0956, p<0.0001$ ). Relative to the software design student group, the high t-values for both B3 and B4 indicate both a meaningful and pronounced difference between the groups in their responses. These four points suggest that students within choreography perceived a more deliberate teaching of collaboration than software design, which supported our observations and interviews with teachers.

B1: The teacher's enthusiasm for small-group work motivated me to collaborate

B2: The teacher guides our small group work and facilitates our ongoing collaboration

B3: The teacher has outlined effective theories and practices for collaboration in small-groups

B4: The course outline/reading materials have outlined effective theories and practices for collaboration in small-groups

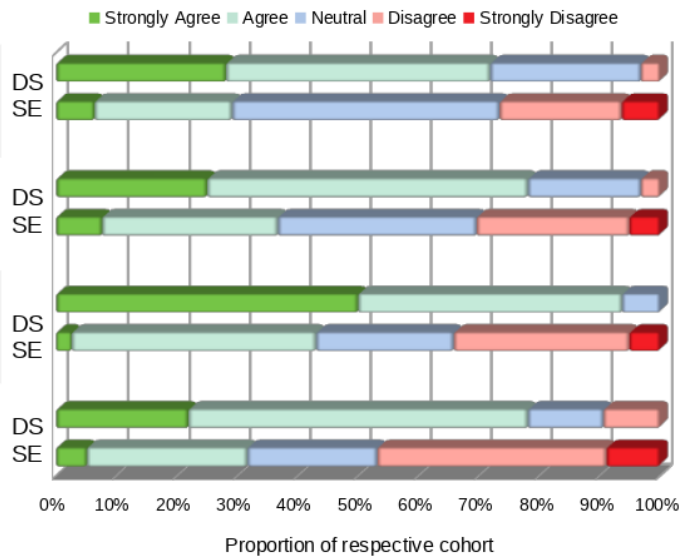

Figure B: teaching collaboration

As teacher's attitudes and behaviors towards a subject can significantly impact student attitudes to the subject (Ađalsteinsdóttir, 2004), how the teacher expresses enthusiasm for collaboration may spread to students. This might involve an enthusiasm for ongoing processes of collaboration, that create, in the words of a Dance Studies student, "a focused environment that urges us to keep going, where we might've thought finished". Another Dance Studies student expressed the importance of the teacher's energy in this process, 
"I think group work can be improved by whoever facilitates the space and allows the group work to happen. This can be done by the energy they set from the get go."

The concept of "allowing" the group work to happen is an interesting insight, in that it acknowledges that this pedagogical attitude can involve a giving-ofpermission, rather than an establishing of boundaries and rules. In the context of socializing classrooms, such a giving of permission can be a necessary step to allow students to move away from a culture of privatized learning. This can require, as one software design student suggested, activating socialization in the classroom, through "more encouragement to meet new people, work with them".

Central to this socialization is the way that groups are formed and how differences are valued within the groups. A choreography teacher explains how and why she purposefully constructs the groups based on differences:

"I try and really mix them up all the time because they will always want to work with their friend... they're forced to figure it out and they don't necessarily figure out their social stuff by talking about it but they figure it out through the creative stuff, so just by doing the task."

By contrast, in software design, a teacher explains how "They get told 'get into pairs' and they decide who they want to work with." This was rationalised as a means of avoiding student contentions over who they are placed with, but also a belief in the value of similarities within small groups, as a software design teacher rationalized, "The groups that take the task seriously often have likeminded individuals together." This familiarity lead to issues monitoring free-riders however, as a software design teacher reflected, "They'll tend to buddy up with their friends and sometimes it's very difficult for them to dob in their mates."

From our observations of classes and interviews with teachers, the software design student groups tended to be composed of more ethnically and culturally homogenous groups than the choreography student groups. The value of teacherguided selection of heterogeneous groups is promoted by a student comment from software design,

"Make sure the people working together are always changing. We need to work with a diverse range of people, including differing backgrounds and skill levels."

Student comments from both groups emphasized a preference for the teacher's selection of groups, an idea supported by previous research (Hansen, 2006).

The teachers also presented very contrasting approaches to the management of problems within the groups. As a choreography teacher explains,

"I' $m$ always looking for social stuff, I' $m$ always looking for the two in the corner who are standing there kind of staring into space not looking at each other with not much action going on and I'll go over and I'll try and figure out what's happening, whether they just don't have the right language or they don't know where to start work or they don't like each 
other or what's going on for those groups that might be a bit dysfunctional."

This proactive engagement with student interactions was reiterated by all of the dance teachers we interviewed. As a software design teachers suggests, this was not perceived as a convention within software design teaching "I think it's fair to say that I don't really follow the groups closely unless there is like, really serious concerns". This is connected to the practice of the group work happening predominantly outside the classroom, as a software design teacher explains, "it can be quite hard to sort of for us to up front know who is communicating and who is not... in terms of keeping an eye on them all I don't think a lot of that happens.... I would say most of the time where there are issues, they tend to be brought to our attention late."

That teachers might provide more active guidance in collaboration was repeatedly expressed by software design students, who sought "more facilitation from lecturers and guidance towards group work". A Software Engineering student further explains why such assistance is necessary at a tertiary level,

"I think, especially early on in our degrees, it's worthwhile having staff supervise group work. The level of professionalism required at a tertiary level isn't necessarily a skill built up in schools. There needs to be some supervision when building a culture of collaboration, so it doesn't spiral away from being useful."

The ways in which collaborative work was theorized was also distinct within the course designs and teaching practices. Within software design, the theorization of group tasks tended to focus on the management of the production process, through reference to differing theories of project management such as Agile and Waterfall (Balaji \& Sundararajan Murugaiyan, 2014). A software teacher explained, "They have a project briefing, but as a group they have to develop a plan how they want to implement the task at a hand, I don't tell them how to do it." Another software teacher expressed, "I didn't really think about any differences about how groups might work together."

Within choreography, the theorization of group work tended to focus more on creative deliberation, through reference to theories on choreographic decisionmaking processes (Butterworth, 2004). In alignment with this, the choreography teachers explained the importance of deliberately focusing on interpersonal skills. As one teacher describes,

"the collaborative skills are things that you can learn to do, and if we can break them down into some real life actions, not just thinking about them hypothetically, we can know what the strategies are."

These differing approaches to the theoretical support for group work appears to have significantly impacted on how students perceived their learning about collaboration. Software design students expressed numerous comments seeking further readings and curricula resources to enhance their understandings of collaborative interactions, including: Structured guides on group work and interacting with others. 
Education resources on how to better interact with partners such as examples, success stories.

To develop shared understandings and expectations of effective collaboration within the class, the software design students also emphasized their desire for the teacher to provide:

More teaching on how to program in groups.

Better discussion for tactics on how to have an effective group.

More guidance towards group work so everyone is on the same page.

The responses from choreography students expressed a stronger sense that guidance is currently provided, which aligned with our classroom observations and interviews with teachers. The ways that the teacher takes responsibility for both facilitating and educating about collaboration therefore appears to be important and worthy of further consideration. These perceived differences in teaching subsequently leads to significant differences regarding the students' sense of learning achievement from group tasks.

\section{What was learnt about group work through these tasks?}

Figure $C$ provides additional evidence for a difference of opinion between the dance and software engineering students. The null hypothesis for $\mathrm{C} 1$ is rejected $(t=4.7710, p<0.0001)$, suggesting that choreography students are significantly more likely to agree that group work has helped with their people skills. Similar results were evident for prompts $\mathrm{C} 2$ and $\mathrm{C} 3$, rejecting the null hypotheses for both. Choreography students were significantly more likely to agree that their knowledge of how to participate in small-group collaborative tasks had expanded $(\mathrm{t}=4.8532, p<0.00001)$ and that group work helped them understand course content $(\mathrm{t}=4.7545, p<0.00001)$. All three prompts from figure $\mathrm{C}$ show that choreography students held more positive learning outcomes regarding collaboration than students in software design.

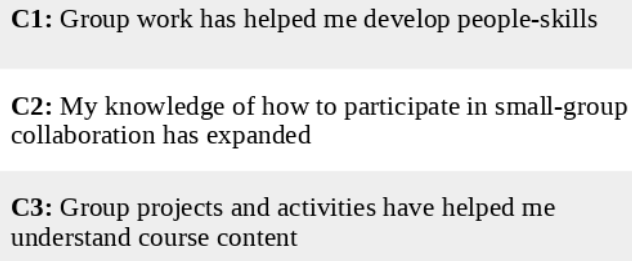

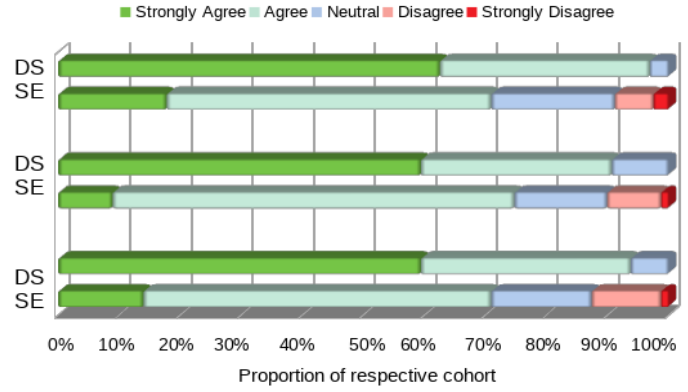

Figure C: Learning about group work

Extending upon these quantitative results, a choreography student further commented that group work helped in "understanding how others work". While the value of observing others in a group was acknowledged as an effective means of developing greater social sensitivity, some students also noted the skills gained by responding to others in a group. A choreography student explained, "I enjoy giving constructive feedback as well as developing materials as a group". Such comments reflect how the students gained a deeper sense of social regulation and 
perspective taking (Oztop, Katsikopoulos \& Gummerum, 2018), as suggested by another choreography student, this involved a balance of "learning when to follow and contribute".

By contrast, the comments of the software design students reflected a belief in the benefits of group tasks in terms of a division-of-labour:

Delegation of tasks for maximum competency.

Being able to specialize on particular tasks.

Workload is distributed, each person can focus on simpler aspects.

These comments suggest that group work processes were cooperative, with individuals working separately and in parallel, rather than collaboratively. As the students explain, this division of labour minimized effort and maximized productivity.

The speed things can be completed.

Having to do less work.

The only comment from a choreography student relating to the scale and effort of group-work challenged this assumption, suggesting "just because there is a bigger group working on it doesn't mean it takes less time."

This distinction in students' perceptions of the learning value of group tasks may relate to the teachers' understandings of what is being evaluated through group tasks. For the software design teachers interviewed, the function of group tasks was predominantly framed in terms of the productivity, as one described how "We tell them that the grade is about what at the end they produce." At the same time, software teachers identified problems that emerged from this focus on productivity. A teacher recalled a "dysfunctional" group that was "kind of a dictatorship" in which one individual did all the work and marginalized the other group members. He describes how the final product "....was good in terms of software implementation, but was very bad in terms of teamwork and learning about the development process, which is an essential part of this course." Another software teacher noted how this focus on productivity meant that some students "not only did not participate, but even did not have a good understanding of what the others had one."

By contrast, choreography teachers explained how the collaborative process was a specific and important item within assessment. As a teacher describes, "that's an objective within the assessment rubric...the criteria was based on how they were discussing their idea, their level of organisation, their ability to critically reflect upon the process and how that went."

Through understanding what the students perceive that they are actually learning regarding group work, and what teachers perceive that they are actually teaching, further distinctions between the two programmes emerged regarding the pedagogic approach to collaboration. These distinctions underpin the contrasting survey results, and ultimately relate to how students perceive the relevance of small-group tasks. 


\section{How relevant is learning and working together?}

Figure D illustrates that while students from both groups think that small-group task-based learning is relevant, students from dance were more likely to present positive responses. We were unable to reject the null hypothesis for prompt D2 $(\mathrm{t}$ $=1.1457, \mathrm{p}=0.2545$ ) with this showing that both groups were similarly likely to agree on the necessity of group learning to their respective disciplines. Stronger contrasts emerged in the responses to D1 $(t=3.1696, p=0.002)$ and D3 $(t=3.3914$, $\mathrm{p}=0.001$ ), both illustrating that choreography students were more likely to perceive group tasks as good practice for professional life and necessary to their learning. While both groups leaned towards a positive perspective, these $p$-values evidence a difference of opinion between the groups, allowing us to reject the null hypothesis in each case.

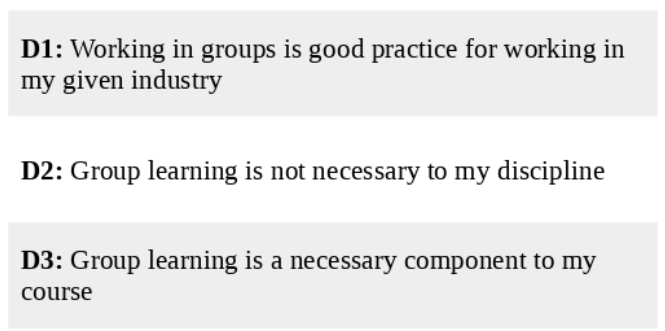

Figure D: Relevance of learning and working together

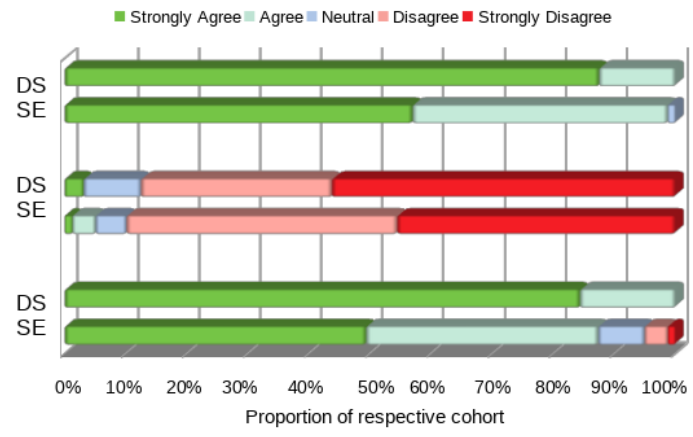

Despite reporting that group work did less to enhance their professional interpersonal skills, software design students nevertheless emphasized the significance of group course work as "very helpful for future industry work" and "industry group tools", emphasizing the belief that, "especially for Software Engineering, group work and ability to work in a team are essential".

Both groups presented comments that emphasized the instrumental function of cooperative learning, as a means of enhancing knowledge in the discipline (Nuthall, 1997). One dance studies student expressed, there is "more analysis of things, talking about a concept or task" and another suggested "[i]t makes learning more fun and easier. It also helps you get a better understanding of the tasks". That students can make valuable contributions to knowledge acquisition was emphasized by a Dance Studies student, who wrote, "learning off each other is what I value because your peers are your greatest teachers."

These sentiments were shared by Software Engineering students, who valued "learning new things from partner" and "learning new solutions to problems from other team members and being able to teach things to other team members that they haven't seen before." This was seen as particularly relevant to enhancing comprehension, "I like how people can build ideas off of each other... in terms of coding, we are able to help each other if one person misses out on a certain aspect of the problem."

One point for consideration from these comments might be that the comments by Dance Studies students predominantly rationalized the importance of this group 
learning in terms of how such tasks allowed them to gain more diverse perspectives, rather than 'right' answers. As a choreography student expressed,

"Everyone's ideas are different but still relevant to the task given. I also

like how people agree with what you say and can incorporate that within other ideas that are said."

While pluralism was also valued by the Software Engineering cohort, the students emphasized how diversity can enhance the final product for assessment, rather than how the diversity can more generally enrich students' perspectives. A software student quantified this as "The ability to use other's ideas. Double creativity." How students value group work might in this way be associated with how teachers assess group work, with a focus on the product (rather than process) leading to a valuing of group-work in terms of productivity, rather than pluralism and innovation.

These distinctions are of significance to institutions that claim that (through group-work) students are expanding not only their abilities, but also their dispositions, to collaborate. So long as the value of group-work remains focused on the efficacy of the productivity, an individual's motivation to engage in group work can remain limited to a sense of economic exchange (Hung et al, 2011).

\section{Conclusion}

We acknowledge that the research presented in the previous pages does not comprehensively represent the diversity and complexity of pedagogical approaches to Dance Studies and Software Engineering (in our university or in tertiary education in general). This study is limited in both scope and scale, conducted in a particular institutional context and within a limited timeframe. Others who may engage in similar studies might discover very different insights. We also acknowledge the logistical contrasts between teaching large student cohorts within lecture halls and teaching smaller student cohorts in studios. However, while the disciplines, cohorts and educational logistics present distinct differences and limitations, we follow Biggs (1996) in arguing for a constructive alignment of curriculum and pedagogic practices; the way we teach should be guided by what are the required graduate outcomes, not by the traditions and logistics of the institute.

Our mixed method approach therefore provides quantitative and qualitative data that reveals that student interest in collaboration is not necessarily guided by their disciplinary interest or demographic background. Such a methodological approach has limitations in what can be explored with the data that is discovered and the scope of one scholarly article, and future studies might dive further into the qualitative or quantitative aspects of what this research opens as starting points. Nevertheless, the data reveals that students who experience a more deliberate teaching of collaboration, experience a greater sense of learning about group work, and subsequently value an ability to work well in groups as a relevant professional skill. This research therefore establishes a platform for further evidenced-based research into how the teaching of collaboration may lead to a shift in the experience of small-group learning tasks. Such research might involve further analyses into how pedagogic practices can support or diminish 
collaboration within groups, and how effective pedagogical approaches to collaboration might be transferred across disciplines. Ultimately, this may provide an effective higher education response to the demands of industry; allowing graduates to enter the workplace with a strong capacity, and inclination, to collaborate on creative endeavors.

\section{References}

Ađalsteinsdóttir, K. (2004). Teachers' behaviour and practices in the classroom. Scandinavian Journal of Educational Research,48(1), 95-113. https:// doi.org/10.1080/0031383032000149869

Amans, D. (2017). An introduction to community dance practice. London, UK: Macmillan International Higher Education.

Balaji, S., \& Sundararajan Murugaiyan, M. (2012). Waterfall vs. V-Model vs. Agile: A comparative study on SDLC. International Journal of Information Technology and Business Management, 2(1), 26-30.

Barksdale, J. T., \& McCrickard, D. S. (2012). Software product innovation in agile usability teams: an analytical framework of social capital, network governance, and usability knowledge management. International Journal of Agile and Extreme Software Development, 1(1), 52-77. https:/ / doi.org/10.1504/IJAESD.2012.048302

Beck, K. (2000). Extreme Programming Explained: Embrace Change. Boston, USA: AddisonWesley Longman.

Biggs, J. (1996). Enhancing teaching through constructive alignment. Higher Education, 32(3), 347-364.

Boden, R., \& Nedeva, M. (2010). Employing discourse: universities and graduate 'employability'. Journal of Education Policy, 25(1), 37-54. https://doi.org/10.1080/02680930903349489

Buck, R., \& Rowe, N. (2015). "Threshold concepts, academic identity and arts curricula design: Dr Who and Indiana Jones traverse learning landscapes for dance". In M. Fleming, L. Bresler \& J. O Toole (Eds.), The Routledge International Handbook of the Arts and Education (pp.170-184). London, UK: Routledge.

Buck, R., \& Snook, B. (2018). Undisciplining arts education: Towards arts integration. Journal of Artistic and Creative Education, 12(1), 21-40.

Burbach, M. E., Matkin, G. S., Gambrell, K. M., \& Harding, H. E. (2010). The impact of preparing faculty in the effective use of student teams. College Student Journal, 44(3), 752-761.

Butterworth, J. (2004). Teaching choreography in higher education: A process continuum model. Research in Dance Education, 5(1), 45-67. https://doi.org/10.1080/1464789042000190870

Chen, C., Wang, Y., Kinshuk, \& Chen, N. (2014). Is FLIP enough? Or should we use the FLIPPED model instead?. Computers \& Education, 79(2014), 16-27. https://doi.org/10.1016/j.compedu.2014.07.004

Cockburn, A. (2006). Agile software development: The cooperative game. London, UK: Pearson Education.

Cohen, E. G. (1994). Restructuring the classroom: Conditions for productive small groups. Review of Educational Research, 64, 1-35. https://doi.org/10.3102\%2F00346543064001001

Creswell, J. (2016). Reflections on the MMIRA the future of mixed methods task force report. Journal of Mixed Methods Research, 10(3), 215-219. https://doi.org/10.1177/1558689816650298 
Csikszentmihalyi, M. (1996). Creativity: Flow and the psychology of discovery and invention. New York, USA: Harper Collins.

Dawson, M. J., \& Jones, M. L. (2003). Human change management: Herding cats. London, UK: Price Waterhouse Cooper.

Denzin, N. K., \& Lincoln, Y. S. (1998). Strategies of qualitative inquiry. Thousand Oaks, USA: Sage.

Dillenbourg, P. (1999). Collaborative Learning: Cognitive and Computational Approaches. Bingley, USA: Elsevier.

Dingwall, R. (1997). Accounts, interviews and observations. Context and method in qualitative research, 51-65.

Fehr, E., \& Gachter, S. (2002). Altruistic punishment in humans. Nature, 415(10 January 2002), 137-140.

Foster-Sproull, S. (2017). Embodied economies: Locating the 'prosumer-dancer' within dnacers' experiences of choreographic practice (Unpublished Master's of Dance Studies thesis). University of Auckland, New Zealand.

Freeman, S., Eddy, S., McDonough, M., Smith, M., Okoroafor, N., Jordt, H., \& Wenderoth, M. (2014). Active learning increases student performance in science, engineering, and mathematics. Proceedings of the National Academy of Sciences of the United States of America, 111(23), 8410-8415. https:/ / doi.org/10.1073/pnas.1319030111

Giacaman, N., \& Sinnen, O. (2018). Preparing the software engineer for a modern multicore world. Journal of Parallel and Distributed Computing, 118(1), 247-263. https:// doi.org/10.1016/j.jpdc.2018.02.028

Griffin, P., \& Care, E. (2015). Assessment and teaching of 21st century skills: Methods and approach. New York, USA: Springer.

Hansen, R. (2006). Benefits and problems with student teams: Suggestions for improving team projects. Journal of Education for Business, 82(1), 11-19. https://doi.org/10.3200/JOEB.82.1.11-19

Hennessy, S., \& Murphy, P. (1999). The potential for collaborative problem solving in design and technology. International Journal of Technology and Design Education, 9(1), 1-36.

Hesse, F., Care, E., Buder, J., Sassenberg, K., \& Griffin, P. (2015). A framework for teachable collaborative problem solving skills. In E. Care, P. Griffin, \& M. Wilson (Eds.), Assessment and teaching of 21st century skills (pp. 37-56). Dordrecht: Springer.

Horder, J. (1995). Inter-professional education for primary health and community care: Present state and future needs. In K. Soothill, L. Mackay \& C. Webb (Eds.), Interprofessional Relations in Health Care. London, UK: Edward Arnold.

Hung, S. Y., Durcikova, A., Lai, H. M., \& Lin, W. M. (2011). The influence of intrinsic and extrinsic motivation on individuals' knowledge sharing behavior. International Journal of Human-Computer Studies, 69(6), 415-427. https://doi.org/10.1016/j.ijhcs.2011.02.004

Jermann, P., \& Dillenbourg, P. (2008). Group mirrors to support interaction regulation in collaborative problem solving. Computers and Education, 51, 279-296. https://doi.org/10.1016/j.compedu.2007.05.012

Johnson, D., \& Johnson, R. (2009). An educational psychology success story: Social interdependence theory and cooperative learning. Educational Researcher, 38(5), 365-379. https://doi.org/10.3102/0013189X09339057

Johnson, R. B., \& Onwuegbuzie, A. (2004). Mixed methods research: A research paradigm whose time has come. Educational Researcher, 33(7), 14-26. https://doi.org/10.3102/0013189X033007014 
Lavender, L. (2009). Dialogical practices in teaching choreography. Dance Chronicle, 32(3), 377-411. https://doi.org/10.1080/01472520903276735

Lavender, L., \& Predock-Linnell, J. (2001). From improvisation to choreography: The critical bridge. Research in Dance Education, 2(2), 195-209. https://doi.org/10.1080/14647890120100809

Lehikoinen, K. (2018). Setting the context: Expanding professionalism in the arts - A paradigm shift. In B. Revelli \& S. B Florander (Eds.), Careers in the Arts: Visions for the Future. (pp. 16-30). Amsterdam, The Netherlands: ELIA.

Mattessich, P., \& Monsey, B. (1992). Collaboration: what makes it work. A review of research literature on factors influencing successful collaboration. St. Paul, USA: Amherst H. Wilder Foundation.

McMahon, K., Ruggeri, A., Kammer, J. E., \& Katsikopoulos, K. V. (2016). Beyond idea generation: The power of groups in developing ideas. Creativity Research Journal, 28(3), 247-257. https://doi.org/10.1080/10400419.2016.1195637

Nahachewsky, A. (1995). Participatory and presentational dance as ethnochoreological categories. Dance Research Journal, 27(1), 1-15. https:// doi.org/10.2307/1478426

Nuthall, G. (1997). Understanding student thinking and learning in the classroom. In B. Biddle, T. Good \& I. Goodson (Eds.), The International Handbook of Teachers and Teaching (pp. 681-768). Dortrecht, Germany: Kluwer.

Owen, D. (2015). Collaborative decision making. Decision Analysis, 12(1), 29-45. https://doi.org/10.1287/deca.2014.0307

Rodgers, D. T. (1982). In search of progressivism. Reviews in American History, 10(4), 113 132. https:// doi.org/10.2307/2701822

Rowe, N. (2019). The great neoliberal hijack of collaboration: a critical history of groupbased learning in tertiary education. Higher Education Research \& Development, 114. https://doi.org/10.1080/07294360.2019.1693518

Rowe, N., Martin, R., Buck, R., \& Mabingo, A. (2020). Teaching collaborative dexterity in higher education: Threshold concepts for educators. Higher Education Research and Development. https://doi.org/10.1080/07294360.2020.1833843

Rowe, N. \& Zeitner-Smith, D. (2011). Teaching creative dexterity to dancers: critical reflections on conservatory dance education in the UK, Denmark and New Zealand. Research in Dance Education, 12(1), 42-51. https://doi.org/10.1080/14647893.2011.556716

Soller, A., Martinez, A., Jermann, P., \& Muehlenbrock, M. (2005). From mirroring to guiding: A review of state of the art technology for supporting collaborative learning. International Journal of Artificial Intelligence in Education, 15(4), 261-290. https://telearn.archives-ouvertes.fr/hal-00197378/

Thapalia, C. F. (1996). Animation and leadership. In J. Servaes, T. L Jaconson, \& S. A. White (Eds.), Participatory Communication for Social Change. (pp. 150-161). New Delhi, India: Sage.

Van Dyke, J. (2005). Teaching choreography: Beginning with craft. Journal of Dance Education, 5(4), 116-124. https:/ / doi.org/10.1080/15290824.2005.10387300

Weiss, R. S. (1994). Learning from strangers: The art and method of qualitative interview studies. New York, USA: The Free Press.

Whitehead, J. (2007). Collaboration in software engineering: A roadmap. In 2007 Future of Software Engineering. (pp. 214-225). IEEE Computer Society. https://doi.org/10.1109/FOSE.2007.4 